\title{
Efektivitas Pemanfaatan Dana bagi Hasil Cukai Hasil Tembakau dalam Bidang Kesehatan di Kota Surakarta Tahun 2018
}

\author{
Febry Wulandaria ${ }^{a}$ Waluyo ${ }^{b}$ \\ a.b Fakultas Hukum, Universitas Sebelas Maret, Surakarta - Indonesia. \\ Email Coresponden: febrywulandari97@gmail.com
}

\begin{abstract}
This study describes the application of Tobacco Excise Revenue Funds in Surakarta City and reviews the Efficiency of Use of Tobacco Excise Revenue Sharing Funds specifically in the Health sector in Surakarta City on 2018. This study is normative legal research, applies to provide an assessment that allows to be applied to conclusions that have been taken. This study uses a syllogism method with a deductive mindset. Primary legal material is a regulation that applies authoritatively, secondary legal material consists of books, legal journals, scientific articles and relevant research results and non-legal material consisting of interviews. The technique of receiving legal material in this legal discussion uses document studies and interviews. This study shows that issuing Profit Sharing Funds for Tobacco Excise in Surakarta City in the Health Sector on 2018 is in accordance with Law Number 39 of 2007 and PMK 222/PMK.07/2017 and has run quite effectively starting from financial performance and realization of program activities even though technical and juridical constraints.
\end{abstract}

Keywords: Excise Revenue Funds, Tobacco, Health, Surakarta City.

\begin{abstract}
Abstrak
Penelitian ini menjelaskan Mekanisme terkait Pelaksanaan Pemanfaatan Dana Bagi Hasil Cukai Hasil Tembakau di Kota Surakarta dan mengkaji Efektivitas Pemanfaatan Dana Bagi Hasil Cukai Hasil Tembakau khususnya dalam Bidang Kesehatan di Kota Surakarta Tahun 2018. Penelitian ini merupakan penelitian hukum normatif, bersifat preskriptif untuk memberikan rekomendasi yang memungkinkan untuk diterapkan berdasarkan pada kesimpulan yang telah diambil. Penelitian ini menggunakan metode silogisme dengan pola pikir deduktif. Bahan hukum Primer merupakan peraturan yang bersifat autoritatif, bahan hukum sekunder terdiri dari buku-buku, jurnal hukum, artikel ilmiah dan hasil penelitian yang relevan serta bahan non hukum berupa hasil wawancara. Teknik pengumpulan bahan hukum dalam penulisan hukum ini menggunakan studi dokumen dan wawancara. Penelitian ini menunjukkan bahwa pemanfaatan Dana Bagi Hasil Cukai Hasil Tembakau di Kota Surakarta dalam Bidang Kesehatan Tahun 2018 sudah sesuai dengan UU Nomor 39 Tahun 2007 dan PMK 222/PMK.07/2017 serta sudah berjalan cukup efektif mulai dari kinerja keuangan maupun realisasi program kegiatan meskipun terdapat kendala teknis maupun yuridis.
\end{abstract}

Kata Kunci: Dana Bagi Hasil Cukai Hasil Tembakau, Kesehatan, Kota Surakarta.

\section{Pendahuluan}

Undang-Undang Dasar Negara Republik Indonesia Tahun 1945 Amandemen ke empat pasal 34 menyebutkan bahwa negara menjamin kesejahteraan masyarakat melalui tiga kunci pokok yaitu di bidang pendidikan, ekonomi dan 
kesehatan. Pokok Kesehatan ditegaskan dalam bunyi Pasal 34 ayat 3 UUD 1945 yang mengatakan bahwa Negara bertanggungjawab dalam penyediaan fasilitas pelayanan kesehatan dan fasilitas pelayanan umum yang layak.

Pemerintah Indonesia melaksanakan amanat undang-undang untuk mencapai derajat kesehatan masyarakat membutuhkan suatu perencanaan anggaran, Perencanaan anggaran sendiri pun sumbernya bermacam-macam salah satunya adalah pendapatan negara dari cukai. Seiring berkembangnya permasalahan mengenai cukai maka upaya yang dilakukan pemerintah Indonesia untuk memberikan kepastian hukum dan keadilan adalah menerbitkan UndangUndang Nomor 39 Tahun 2007 tentang Perubahan atas Undang-Undang Nomor 11 Tahun 1995 tentang Cukai. UU 39/2007 mengatur hal baru diantaranya mengenai Dana Bagi Hasil (DBH) dari Cukai Hasil Tembakau (CHT) kepada pemerintah daerah penghasil CHT (Pasal 66A s/d 66D). DBH-CHT adalah dana yang bersumber dari APBN, tepatnya adalah penerimaan negara dari $\mathrm{CHT}$ yang dibuat di Indonesia, dibagikan kepada provinsi penghasil CHT sebesar 2\% (dua persen), membantu daerah penghasil CHT melaksanakan kebijakan pemerintah pusat, guna meningkatkan penerimaan negara dari sektor CHT serta mengatasi dampak rokok terhadap kesehatan (Insana Meliya Dwi Cipta Aprila Sari, 2010:70). Berdasarkan PMK Nomor 222/PMK.07/2017 tersebut menyebutkan dalam Pasal 2 ayat 2 bahwa DBH-CHT untuk mendanai program diprioritaskan untuk mendukung program Jaminan Kesehatan Nasional paling sedikit 50\% dari alokasi DBH-CHT yang diterima setiap daerah.

Peraturan Presiden (Perpres) mengenai pemanfaatan cukai rokok dan pajak rokok untuk menutup defisit keuangan Badan Penyelenggara Jaminan Sosial (BPJS) Kesehatan, rupanya menuai dilema. Regulasi rokok dalam (Budi Ispriyarso, 2018:229) ibarat dua mata pisau yang "menjebak" dalam situasi yang dilematis. Di satu sisi, industri rokok memberikan masukan terhadap penerimaan negara, namun di sisi lainnya pemerintah juga menanggung dampak negatif rokok yang dapat meningkatkan anggaran kesehatan.

Pemerintah berkewajiban untuk menjaga kesehatan masyarakat, oleh karena itu maka perlu terus peningkatan pendanaan untuk keperluan penjagaan kesehatan masyarakat salah satunya menjadikan DBH-CHT sebagai sumber pendanaan defisit BPJS merupakan solusi yang tepat mengingat masih banyaknya ditemukan permasalahan administrasi dan pengawasan dalam implementasi dana earmarking DBH-CHT di daerah yang belum optimal.

Sebagai daerah penghasil cukai hasil tembakau, maka Kota Surakarta mendapat persentase alokasi yang cukup tinggi dari DBH-CHT. Dalam pelaksanaannya, DBH-CHT yang diterima dan digunakan di Kota Surakarta masih perlu untuk terus dipantau dan dievaluasi. Salah satunya karena pemahaman masyarakat yang kurang terhadap peruntukan dan pemanfaatan DBH-CHT. DBH-CHT harus diimplementasikan secara efektif sehingga mampu meningkatkan taraf hidup masyarakat dan mendukung program-program kegiatan seperti yang telah diamanatkan undang-undang. 


\section{Metode Penelitian}

Jenis penelitian yang digunakan dalam menyusun penelitian hukum ini adalah penelitian hukum normatif atau doktrinal, yaitu penelitian berdasarkan bahan-bahan hukum yang mempelajari bahan-bahan hukum primer dan sekunder, menemukan apakah aturan hukum yang ada sudah sesuai dengan norma hukum, apakah norma yang berupa perintah atau larangan itu sesuai dengan prinsip hukum dan apakah tindakan seseorang sudah sesuai dengan norma hukum atau prinsip hukum (Peter Mahmud Marzuki, 2014 : 47).

Penulisan hukum ini merupakan penulisan hukum normatif yang bersifat preskriptif. Pendekatan yang digunakan adalah pendekatan perundangundangan (statute approach). Teknik pengumpulan bahan hukum dari penelitian ini studi dokumen dan wawancara dengan menggunakan teknik analisa bahan hukum metode silogisme dengan melalui pola berfikir deduksi.

\section{Hasil dan Pembahasan}

Berlakunya UU No 23 Tahun 2014 tentang Pemerintahan Daerah dan UU No 33 Tahun 2004 tentang Perimbangan Keuangan antara Pemerintah Pusat dan Pemerintahan Daerah, maka penyelenggaraan pemerintahan daerah dilakukan dengan memberikan kewenangan yang seluas-luasnya, disertai dengan pemberian hak dan kewajiban menyelenggarakan otonomi daerah dalam kesatuan sistem penyelenggaraan pemerintahan negara. Peningkatan Pendapatan Asli Daerah merupakan salah satu indikator kesiapan daerah dalam menjalankan kebijakan otonomi. Pemerintahan daerah Kota Surakarta mempunyai peluang untuk memperbaiki kualitas pembangunan kota Surakarta salah satunya dengan berbagai jenis pungutan terhadap rokok di Indonesia antara lain Pajak Pertambahan Nilai Rokok, Pajak Rokok dan Cukai Rokok.

Sesuai dengan ketentuan UU 39/2007 Pasal 66A ayat (1) menyebutkan bahwa Penerimaan negara dari CHT yang dibuat di Indonesia dibagikan kepada provinsi penghasil CHT sebesar $2 \%$ yang digunakan untuk mendanai peningkatan kualitas bahan baku, pembinaan industri, pembinaan lingkungan sosial, sosialisasi ketentuan di bidang cukai, dan/atau pemberantasan barang kena cukai ilegal serta tingkat pengalokasian DBHCHT Kota Surakarta tahun 2017-2018 yang jauh lebih besar dibandingkan alokasi DBHCHT pertama kali tahun 2008, DBHCHT dapat diandalkan untuk meningkatkan pendapatan kota Surakarta. Kota Surakarta sendiri mengejewantahkan instruksi dari UU 39/2007 Pasal 66A ayat (1) tersebut dengan melaksanakan hanya 4 program dari 5 program yang didanai DBHCHT karena program Peningkatan Kualitas Bahan Baku bukan termasuk karakteristik daerah Kota Surakarta dengan daerah penghasil tembakau.

Tahun 2018 dalam Laporan Penggunaan DBHCHT Pemerintah Kota Surakarta telah melakukan Pembinaan Industri (Pendataan dan Pengawasan kepemilikan/ penggunaan mesin pelinting rokok di 4 Pabrik-pabrik rokok di Kota Surakarta oleh OPD DISNAKER PERIN \& Pembinaan dan Peningkatan Kapasitas sumberdaya manusia pada usaha Industri Hasil tembakau skala kecil oleh OPD DISNAKER PERIN), Sosialisasi Ketentuan Di Bidang Cukai (Koordinasi 
Pelaksanaan Penggunaan DBHCHT berupa Monitoring Evaluasi Penggunaan Dana Cukai oleh Bagian Perekonomian), Pemberantasan Barang Kena Cukai Ilegal (operasi pemberantasan Barang Kena Cukai di sejumlah pedagang eceran/toko yang menjual produk tembakau dan pendataan produk tembakau di 51 Kelurahan oleh OPD Satpol PP), dan Pembinaan Lingkungan Sosial (Pelatihan Pengolahan diversifikasi makanan sebanyak 15 orang bagi lingkungan Industri Hasil Tembakau dan Pemagangan dan uji kompetensi peserta pelatihan diversifikasi makanan sebanyak 15 orang bagi lingkungan Industri Hasil Tembakau oleh DISNAKER PERIN.

Pelatihan keterampilan dan praktek belajar kerja bagi anak terlantar berupa Pelatihan ketrampilan menjahit dan pelatihan ketrampilan sablon agar siap kerja di Industri oleh DINSOS; Pembinaan ketrampilan dan pendidikan berwirausaha bagi ex penyandang penyakit sosial berupa pelaksanaan dan pelatihan ketrampilan boga, salon dan rias pengantin; Penyediaan sarana dan prasarana pengelolaan persampahan berupa sosialisasi Bank Sampah dan Pemberian bantuan/ fasilitasi peralatan Bank Sampah; Pembangunan dan Penataan Ruang Terbuka Hijau berupa Pembangunan Ruang Terbuka Hijau di Taman Jayawijaya Mojosongo oleh DLH; Pembinaan dan pelatihan ketrampilan bagi pencari kerja berupa tersedianya tenaga kerja terampil dan siap kerja, output 62 orang oleh STP; Pengadaan alat-alat kesehatan rumah sakit berupa terpenuhinya alat kesehatan untuk instalasi kamar operasi oleh RSUD; Pengadaan alat-alat kesehatan rumah sakit berupa pengadaan mobil ambulan dan peralatannya untuk Puskesmas Nusukan, Stabelan, Gajahan dan DKK sebanyak 4 unit oleh DKK; Pembayaran iuran Jaminan Kesehatan bagi penduduk yang didaftarkan oleh Pemerintah Daerah atau bagi pekerja yang terkena pemutusan hubungan kerja berupa terbayarnya iuran Jaminan Kesehatan untuk Pemeliharaan dan Pemulihan Kesehatan Premi JKN KIS oleh DKK).

Sesuai ketentuan Pasal 66A ayat (3) UU No 39/2007 tentang Cukai menyatakan bahwa Gubernur mengelola dan menggunakan DBHCHT dan mengatur pembagian DBHCHT kepada Bupati/Walikota di daerahnya masingmasing berdasarkan kontribusi penerimaan cukai hasil tembakaunya serta sesuai dengan UU Cukai Pasal 66B yang menyebutkan bahwa Penyaluran DBHCHT dilakukan dengan cara pemindahbukuan dari rekening kas umum negara ke rekening kas umum daerah provinsi dan rekening kas umum daerah kabupaten/kota yang mana Kota Surakarta mengelola dibawah kewenangan BPPKAD. Kedua hal tersebut dibenarkan oleh Ibu Tiram Bumi Tanjung selaku Kasubag Perindustrian dan Penanaman Modal Sekretariat Daerah Kota Surakarta (hasil wawancara pribadi tanggal o3 Januari 2019).

\section{Mekanisme Pemanfaatan DBHCHT di Kota Surakarta}

Mekanisme pemanfaatan DBHCHT di Kota Surakarta, Bapak Zufar selaku Analis Bagian Perekonomian Sekretaris Daerah Kota Surakarta menjelaskan yaitu menggunakan SOP DBHCHT (berdasarkan hasil wawancara pribadi tanggal 10 Januari 2019), namun dalam pelaksanaannya tidak dilaksanakan sepenuhnya dengan pertimbangan agar dapat lebih cepat dan 
efektif. Dimulai Organisasi Perangkat Daerah (OPD) membuat usulan anggaran dan menyampaikan rancangan program kegiatan masing-masing dengan output Draf Rencana Program Kegiatan DBHCHT, Kemudian dari OPD dan TAPD mengadakan konsolidasi rancangan program kegiatan dengan output Rencana Program Kegiatan DBHCHT selanjutnya dengan perantara Staf, Subag Perindustrian dan PM, rencana tersebut dikirimkan kepada Walikota melalui Kepala Bagian Perekonomian. Konsolidasi rancangan program kegiatan dari Walikota kepada Gubernur melalui Kabag Perekonomian selanjutnya disampaikan kepada Gubernur dan dilanjutkan kepada Menkeu dengan output Dokumen.

Langkah berikutnya mengirimkan rancangan program kegiatan kepada Kemenkeu DJPK melalui Gubernur, Penyampaian alokasi DBHCHT yang sudah dibahas antara Gubernur dengan Tim Panitia Anggaran maka apabila usulan tersebut disetujui, Kemenkeu DJPK ke Walikota melalui Gubernur menyerahkan uang yang ada di kas daerah kepada OPD-OPD yang bersangkutan sesuai jumlah dari usulan tersebut dengan bentuk Keputusan Alokasi. Setelah alokasi sudah dapat diketahui maka OPD-OPD terkait dapat melaksanakan program kegiatan sesuai alokasi DBHCHT dengan kurun waktu 2 semester, untuk pelaporan program kegiatan dan realisasi DBHCHT dari OPD kepada Walikota melalui Kabag Perekonomian. Kemudian Walikota melaporkan kegiatan DBHCHT kepada Kemenkeu DJPK melalui Gubernur dengan output Dokumen Laporan Kegiatan. Setelah itu diteruskan laporan kegiatannya kepada Kabag Perekonomian, Subag Perindustrian dan PM, dan Staf untuk dapat diarsipkan. Berikut merupakan alur SOP DBHCHT.

Setiap Pelaporan penggunaan DBHCHT dari Sekda Perekonomian Kota Surakarta dari tahun ke tahun kepada Gubernur, maka laporan tahun 2018 dapat dihitung nilai efektivitasnya sebagai berikut, Diketahui Alokasi Anggaran DBHCHT Kota Surakarta Tahun 2018 menurut Lampiran Pergub 7/2018 sebesar Rp 6.580.938.0oo, sedangkan realisasi anggaran DBHCHT Kota Surakarta Tahun 2018 menurut Laporan Program Kegiatan DBHCHT Pemerintah Kota Surakarta TA 2018 Semester 2 sebesar Rp 6.814.36o.876, apabila di masukkan kedalam rumus nilai efektivitas yaitu sebagai berikut:

$$
\begin{aligned}
\text { Efektivitas }: & \frac{\operatorname{Rp} 6.814 .360 .876}{\operatorname{Rp} 6.580 .938 .000} \times 100 \\
= & 103,54 \%
\end{aligned}
$$

Sesuai dengan keputusan Menteri Dalam Negeri nomor 690.900.-327 tahun 1996 tentang pedoman penilaian kinerja keuangan, maka kriteria efektivitas kinerja keuangan DBHCHT Kota Surakarta Tahun 2018 dengan persentase efektivitas 103,54\% dikatakan Sangat Efektif. Kriteria sangat efektif tersebut apabila di sinkronkan dengan program-program yang terealisasi dilapangan sebenarnya belum dapat dikatakan sebagai program kegiatan yang berjalan sangat efektif seperti halnya pendapat Susilo (1992) dalam (Rahardjo, 2014 : 170) bahwa efektivitas adalah suatu kondisi dimana dalam memilih 
tujuan yang hendak dicapai dan sarana atau peralatan yang digunakan, disertai tujuan yang diinginkan dapat dicapai dengan hasil yang memuaskan.

Tetapi ditemukan fakta dalam pemanfaatan DBHCHT Surakarta tujuan yang diinginkan mungkin tercapai tapi dengan hasil yang tidak memuaskan yaitu terjadi beberapa kali perubahan anggaran karena untuk menyesuaikan dengan kondisi di lapangan misalnya saja di Tahun 2018 menurut keterangan Bapak Zufar dan Ibu Tiram (berdasarkan hasil wawancara terpisah tanggal o3 dan 10 Januari 2019) adapun OPD penerima DBHCHT yaitu Disperin saat mengadakan pelatihan ketrampilan pegawai pabrik rokok, karena di DBHCHT Surakarta terdapat aturan peserta yang mengikuti kegiatan DBHCHT oleh Disperin harus penduduk Kota Surakarta, padahal kebanyakan pegawai pabrik-pabrik tersebut dari luar Surakarta maka terjadilah kekurangan jumlah peserta sehingga mengakibatkan dana nya tidak terserap semua.

Contoh yang kedua yaitu Dinsos mengadakan pelatihan penyakit masyarakat semisal Wanita Tuna Susila (WTS), pelatihan ketrampilan bagi penyandang cacat dan anak terlantar, terdapat kendala yaitu kesulitan mencari orang dengan kriteria tersebut sehingga menghambat jalannya program kegiatan. Akibatnya di Tahun berikutnya Dinsos tidak diikutkan lagi dalam OPD Penerima DBHCHT dikarenakan memasang peruntukannya susah diimplementasikan dan menghindari dana tidak terserap di akhir tahun, akhirnya kegiatannya dialihkan pada pembayaran iuran JKN di akhir agar lebih bermanfaat, begitu pula DISNAKER PERIN di 2019 juga dihilangkan kegiatannya yaitu membuat standarisasi kompetensi terhadap pekerja rokok kesulitan dalam mencari yang berkompeten karena accesor nya dari perusahaan besar, sedangkan dari Surakarta kebanyakan perusahaan rokok menengah.

Faktor yang menjadi penghambat dalam DBHCHT dari Provinsi adalah Permasalahan teknis yaitu mengenai seringnya mengalami keterlambatan pencairan alokasi DBHCHT untuk Kota Surakarta juga dikatakan sebagai kendala dalam memprediksi atau menetapkan target pada tahun berikutnya, menurut keterangan lebih lanjut dari hasil wawancara dengan Bapak Zufar (tanggal 1o Januari 2019) yaitu kegiatan DBHCHT baru dilaksanakan semester II, karena semester I menunggu alokasi. Sehingga para tim DBHCHT Kota Surakarta menggunakan asumsi angka tahun lalu dan otomatis menjadi penghambat pemanfaatan DBHCHT di Kota Surakarta. Kendala teknis lain yang ditemukan penulis adalah tidak tersedianya laman khusus dari Pemerintah Kota Surakarta untuk akses publik dalam rangka transparansi penggunaan DBHCHT.

Sedangkan yang ditemukan oleh penulis hanyalah laman online tranparansi anggaran APBD, dimana penggunaan DBHCHT masih bercampur dengan anggaran lain. Kendala yuridis menurut penjelasan Bapak Zufar (dalam wawancara pribadi tanggal 10 Januari 2019) dimana OPD-OPD merasa aturannya terlalu rigid dan dibatasi pengunaannya yang terlalu spesifik sebab belum mengetahui sumber dana nya dari cukai rokok dan CHT dimana peruntukannya tidak boleh semena-mena. Kendala tersebut ditemukan 
penulis di lapangan adalah hingga Tahun 2018 belum ada landasan hukum maupun petunjuk teknis yang khusus untuk mengatur pelaksanaan penggunaan earmarking DBHCHT pada tingkat Kota, sehingga programprogram dan kegiatan yang dilakukan oleh OPD benar-benar mengikuti PMK 222/PMK.07/2017 saja.

\section{Efektivitas Pemanfaatan DBHCHT dalam Bidang Kesehatan di Kota Surakarta}

Pemanfaatan DBHCHT dalam bidang Kesehatan di Kota Surakarta diberikan kepada 2 OPD yaitu DKK dan RSUD. Fokus penelitian penulis disini adalah penyelenggaraan oleh DKK Surakarta. DBHCHT di bidang kesehatan terbagi jadi dua yaitu untuk pelayanan kesehatan dasar dan pelayanan kesehatan rujukan. Pelayanan Kesehatan Dasar dialokasikan ke DKK. Sedangkan Pelayanan Kesehatan Rujukan di Surakarta dialokasikan di RSUD. Melalui Pra Penelitian dengan Ibu Purwanti, SKM., M.Kes., selaku Sekretaris Dinas Kesehatan Kota Surakarta (hasil wawancara pribadi tanggal 26 Oktober 2018), penulis mendapatkan informasi bahwa pemanfaatan DBHCHT dalam Bidang Kesehatan di Dinas Kesehatan Kota Surakarta selama ini digunakan untuk pelayanan kesehatan umum atau pelayanan kesehatan khusus pada yang berhubungan dengan rokok. DKK dalam kesekretariatannya yang berwenang dalam perencanaan, kronologis dan penggunaan DBHCHT itu di Sub Bagian Perencanaan, Evaluasi, dan Pelaporan (PEP).

Menurut keterangan Pak Budiyono, ST, M.Si selaku Kasubag PEP DKK Surakarta (hasil wawancara pribadi tanggal 21 Desember 2018) mengatakan bahwa DKK termasuk OPD Pengguna DBHCHT sejak Tahun 2008. Kewenangan DKK sebagai OPD Penerima DBH CHT adalah diberikannya kuasa menggunakan anggaran tapi tidak keluar dari petunjuk teknis PMK 222/PMK.07/2017 yang telah ditetapkan untuk merencanakan penggunaan DBHCHT. Permenkes sendiri belum mengatur tentang penggunaan DBHCHT.

Dana yang diterima DKK Surakarta dari Kas Daerah Kota Surakarta terkait DBHCHT yaitu 65\% dari Alokasi DBHCHT yang diterima Pemerintah Kota Surakarta, DBHCHT yang diterima oleh Kota Surakarta tahun 2018 adalah sebesar Rp 6.580.938.ooo. DBHCHT yang diterima oleh DKK pada tahun 2018 adalah 65\% dari total Rp 6.580.938.0oo yaitu berjumlah Rp. 4.465.000.0oo adapun Pengadaan Sarana dan Prasarana yang mengelola DKK secara langsung, namun untuk pembayaran premi baru ada di Tahun 2018. Menurut penjelasan dari Pak Budi (hasil wawancara pribadi tanggal o3 Januari 2019) adapun Premi JKN tersebut tetap dikelola oleh DKK dari segi kepesertaan dan jumlah peserta yang dibiayai, dengan alokasi $\mathrm{Rp}$ 3.000.000.00o itu untuk membayar Premi JKN masyarakat kepada pelayanan (Yankes) untuk dikelola lebih lanjut dan kemudian disetorkan ke BPJS Kesehatan.

Mekanisme pemanfaatan DBHCHCT di DKK dari tahun ke tahun sistemnya sama yaitu membuat usulan penggunaan dana DBHCHT ke bagian tim pengampu Kestra Sekda Bagian Perekonomian Kota Surakarta, kemudian usulan tersebut dimasukkan kedalam DPA, setelah itu DKK tiap bulan 
membuat laporan tentang realisasi pemanfaatan DBHCHT. Sedangkan untuk yang bertugas memonitoring pelaksanaan DBHCHT di DKK maupun OPDOPD pengguna DBHCHT di Kota Surakarta lainnya yaitu bagian Kestra, sedangkan untuk yang bertanggung jawab dalam penggunaan DBHCHT oleh DKK yaitu Kepala Dinas dibantu kepala bagian nya.

Bahwa sesuai dengan ketentuan PMK No 222/PMK.07/2017 Pasal 2 Ayat (2) yang menyatakan bahwa program/kegiatan yang didanai DBHCHT (lima program) diprioritaskan untuk mendukung program Jaminan Kesehatan Nasional paling sedikit sebesar 50\% dari alokasi DBHCHT yang diterima setiap daerah. Program-program DBHCHT yang direncanakan dan yang terealisasi oleh DKK Tahun 2018 terkait Pelayanan Kesehatan Dasar dialokasikan untuk 2 program yaitu Pengadaan Ambulans dan Pembayaran Premi JKN, berdasarkan keterangan yang didapat dari Pak Budi (hasil wawancara pribadi tanggal 03 Januari 2019) Program Pengadaan ambulans dilakukan atas pertimbangan berdasarkan urgensi kebutuhan dan menggunakan proses E-Katalog, Sedangkan Premi JKN sudah sesuai ketentuan PMK No 222/PMK.o7/2017 yaitu minimal 50\% dari alokasi DBHCHT.

Peran DKK pada Porsi Preventif terhadap orang terdampak rokok, selama ini sifat nya hanya Preventif misalnya menerbitkan Perwali kaitannya Kawasan Tanpa Rokok (KTR), ada Kader Anti Asap Rokok, Sosialisasi dengan Booklet, Selebaran, Media Massa, semuanya itu menggunakan dana APBD di luar DBHCHT. Sedangkan data dalam Laporan Program Kegiatan DBHCHT Pemerintah Kota Surakarta TA 2018 Semester 2 kepada Gubernur Provinsi Jawa Tengah c.q. Biro Perekonomian Setda Provinsi Jawa Tengah Pengadaan alat-alat kesehatan rumah sakit oleh DKK Surakarta realisasi anggaran sebesar Rp 1.108.778.80o dengan Rencana Anggarannya sebesar Rp 1.240.000.000 dalam uraian rincian kegiatan telah digunakan Pengadaan mobil ambulan dan peralatannya (4 unit) untuk Puskesmas Nusukan, Setabelan, Gajahan dan DKK Gawat Darurat serta digunakan pula untuk Pembayaran Iuran Jaminan Penduduk yang didaftarkan kesehatan bagi oleh Pemerintah Daerah (Pemeliharaan dan Pemulihan Kesehatan Premi JKN KIS) dengan realisasi anggaran sebesar $R p \quad \mathbf{2 . 7 6 4 . 8 8 2 . 1 0 6}$ dan rencana anggaran perubahan sebesar Rp 3.225.00o.ooo. Apabila dijumlahkan total realisasi nya sudah sesuai dengan laporan realisasi penggunaan DBHCHT Tahun Anggaran 2018 oleh DKK Surakarta yaitu total realisasi anggaran sebesar Rp 3.873.660.906. Rencana Anggaran di Laporan realisasi DKK untuk pembayaran premi JKN KIS masih Rp 3.000.000.00o (sebelum perubahan) agar sesuai instruksi dari PMK 222 DBHCHT untuk JKN 50\% maka di laporan perubahan dicantumkan Premi JKN sebesar Rp 3.225.0oo.ooo dengan total anggaran Rp 4.240.000.000 yang dilaporkan DKK dan total $R p$ 4.465.000.00o yang dilaporkan ke Gubernur. Sehingga dapat dihitung nilai keefektifannya, yaitu :

$$
\begin{aligned}
\text { Efektivitas }: \frac{\operatorname{Rp} 3.873 .660 .906}{\operatorname{Rp} 4.465 .000 .000} \\
=86,75 \%
\end{aligned}
$$


Sesuai dengan keputusan Menteri Dalam Negeri nomor 690.900.-327 tahun 1996 tentang pedoman penilaian kinerja keuangan, maka kriteria efektivitas kinerja keuangan DBHCHT DKK Surakarta Tahun 2018 dengan persentase efektivitas 86,75 \% dikatakan Cukup Efektif. Menurut Clerence J Dias ( Clerence J.Dias, 1975 : 150) an effective legal system may be describe as one in which there exists a high degree of congruence beetween legal rule and human conduct. Thus anda effective legal system will be characterized by minimal disparyti beetween the formal legal system and the operative legal system is secured by 1 . The intelligibility of it legal system, 2. High level public knowledge of the conten of the legal rules, 3. Efficient and effective mobilization of legal rules, 4. Dispute sattelment mechanisms that are both easily accessible to the public and effective in their resolution of disputes and, 5. A widely shere perception by individuals of the effectiveness of the legal rules and institutions.

Kelima syarat bagi efektif tidaknya suatu sistem hukum tersebut apabila diejawantahkan dalam administrasi pemanfaatan DBHCHT oleh DKK Surakarta yaitu 1. Aturan-aturan DBHCHT belum mudah difahami maknanya, 2. Masih belum luasnya kalangan masyarakat yang mengetahui isi aturanaturan DBHCHT dalam bidang Kesehatan, dan 3. Belum efisiennya mobilisasi aturan hukum tentang DBHCHT dengan penglibatan masyarakat yang merasa seharusnya untuk berpartisipasi. Indikator keberhasilan penerapan PMK Nomor 222/PMK.07/2017 terhadap Pemanfaatan Dana Bagi Hasil Cukai Hasil Tembakau dalam Bidang Kesehatan di Kota Surakarta Tahun 2018 ditinjau dengan teori efektivitas hukum menurut Satjipto Rahardjo dipengaruhi oleh 3 faktor, yaitu;

1. Faktor Substansi Kaidah Hukum

Ditinjau dari faktor substansi kaidah hukum nya aturan yang mengatur mengenai pemanfaatan DBHCHT baik dari UU Cukai, PMK 222/PMK.07/2017 maupun Pergub 7/2018 sudah baik, meskipun belum ada petunjuk teknis tingkat Kota yang dapat digunakan sebagai acuan agar lebih mudah dalam mencapai tujuan yang diamanatkan peraturan diatasnya, sedangkan yang terjadi pada pemanfaatan DBHCHT dalam Bidang Kesehatan adalah keberhasilan penerapan prosedur penggunaan DBHCHT di Bidang Kesehatan sudah dilakukan walaupun dari pihak Pemerintahan Kota Surakarta khususnya DKK kurang maksimal, karena program-program kegiatan yang berkaitan langsung terhadap terdampak rokok masih disokong dengan dana APBD bukan dari DBHCHT.

2. Faktor Aparatur Penegak Hukum

Ditinjau dari faktor aparatur penegak hukum belum maksimal dikarenakan dalam kasus pelanggaran hukum terhadap tindakan preventif pada tujuan dibentuknya DBHCHT yaitu masih lemahnya pengawasan pada Kawasan Tanpa Rokok di Kota Surakarta karena masih banyak di lingkungan pendidikan maupun ruang publik yang merupakan kawasan tanpa rokok banyak dijumpai orang yang merokok, minimnya penegakan hukum untuk akses yang terlalu mudah bagi anak dibawah umur yang membeli rokok, dan masih minim respon dari pihak yang 
berwenang atas penegakan hukum terhadap iklan rokok di jalanan kota Surakarta yang notabene sudah menjadi kota layak anak sudah seharusnya kawasannya ramah lingkungan. Perlu ada upaya yang maksimal dari beberapa pihak yang berwenang dalam hal ini Satpol PP dalam menindak pelanggaran hukum yang dilakukan oleh masyarakat dalam atau luar Surakarta.

3. Faktor Kesadaran Hukum

Masyarakat mempunyai peran penting dalam perlindungan hukum terhadap pemanfaatan DBHCHT. Minimnya kesadaran hukum masyarakat terhadap peruntukan alokasi DBHCHT menyebabkan kurang kontribusi atas peran masyarakat dan perlu adanya koordinasi yang lebih lagi antara masyarakat dengan pemerintah daerah Surakarta. Supaya setiap program-program kegiatan yang didanai DBHCHT dapat termanfaatkan dengan baik, dan tidak ada lagi kejadian kekurangan peserta yang mengakibatkan dana tidak terserap.

\section{Penutup}

Pemanfaatan DBHCHT di Kota Surakarta Tahun 2018 secara garis besar sudah sesuai dengan UU Cukai Pasal 66B dan sudah sesuai dengan petunjuk teknis PMK 222/PMK.07/2017 dari mulai awal penyusunan sampai pelaporan dengan telah melaksanakan Pasal 66A ayat (1) PMK 222/PMK.07/2017 yaitu melaksanakan 4 program dari 5 program yang didanai DBHCHT, dan telah melaksanakan Pasal 66A ayat (3) yang di realisasikan dengan Pergub 7/2018. Mekanisme pemanfaatan DBHCHT tersebut dengan bantuan SOP DBHCHT. Kriteria efektivitas kinerja keuangan DBHCHT Kota Surakarta Tahun 2018 dengan persentase efektivitas 103,54\% dikatakan Sangat Efektif. Kriteria sangat efektif tersebut apabila di sinkronkan dengan program-program yang terealisasi dilapangan belum dapat dikatakan sebagai program kegiatan yang berjalan sangat efektif dikarenakan hasil yang didapat kurang maksimal dalam mencapai cita-cita tujuan disebabkan terdapat kendala yuridis maupun teknis dalam pemanfaatannya. Efektivitas Pemanfaatan DBHCHT dalam Bidang Kesehatan di Kota Surakarta Tahun 2018 oleh DKK Surakarta dapat dinilai dari pelayanan dasar yang bersifat preventif telah mengikuti pedoman juknis PMK 222/PMK.o7/2017 yakni pengadaan sarana prasana berupa pengadaan 4 ambulan berdasarkan urgensi kebutuhan dan Pembayaran Premi JKN berlandaskan amanat dari PMK 222/PMK.o7/2017 pasal 2 ayat (2), namun penilaian efektivitas tidak bisa hanya diukur dari pelayanan dasar yang bersifat preventif karena pemanfaatan tersebut masih belum optimal dimanfaatkan untuk kegiatan kuratif.

\section{References}

Abdulatti Abdullah Algonin, Ashabani Mohamed Shleag, Gusti Ayu Ketut Rachmi Handayani and Prabang Setyono, "Variation of Environmental Awareness among the Student in Government High Schools in Solo City Indonesia”, International Journal of Applied Engineering Research Volume 9, Number 21 (2014) 
Agus Surachman, I Gusti Ayu Ketut Rachmi Handayani and Yudho Taruno, "Effect of Globalization on Establihment of Water Resource Law: A Practice in Indonesia", International Journal of Economic Research, Volume 14, Number 13 (2017).

Budi Ispriyarso. 2018. "Fungsi Reguler Pajak Rokok di Bidang Kesehatan Masyarakat dan Penegakan Hukum”. Jurnal Masalah-masalah Hukum. Jilid 48/Nomor 03/Juli/2018.

Clarence J.Dias. 1975. "Research on Legal Services and Poverty: Its Relevance to the Design og Legal Services Programs in Developing Countries". Washington University Law Review. Vol 1975/147.

Insana Meliya Dwi Cipta Aprila Sari. 2010. "Dana Bagi Hasil (DBH) Cukai Hasil Tembakau ditinjau dari Cukai Rokok, Kesehatan dan Industri Rokok.” Jurnal Yuridika. Vol.25/ No.1/JanuariApril/2010.

Lego Karjoko, Yulfitri Nurjanah, "The Legality of Freehold Title and Legal Implications Against of Land Makers Officers (The Study of Freehold Title Issuance Number 1576/Nusukan Village, Banjarsari Sub-District, Surakarta City, Central Java)", International Journal of Scientific and Technology Research 8(10), 2019.

Peter Mahmud Marzuki. 2014. Penelitian Hukum Edisi Revisi. Jakarta : Kencana.

Rahardjo Adisasmita. 2014. Pengelolaan Pendapatan dan Anggaran Daerah. Yogyakarta : Graha Ilmu.

Undang-Undang Dasar Negara Republik Indonesia Tahun 1945.

Undang-Undang Nomor 39 Tahun 2007 tentang Perubahan atas Undang-Undang Nomor 11 Tahun 1995 tentang Cukai.

Peraturan Presiden Nomor 82 Tahun 2018 tentang Jaminan Kesehatan.

Peraturan Menteri Keuangan Nomor 222/PMK.07/2017 tentang Penggunaan, Pemantauan dan Evaluasi Dana Bagi Hasil Cukai Hasil Tembakau.

Peraturan Menteri Dalam Negeri Nomor 13 Tahun 2006 Tentang Pengelolaan Keuangan Daerah.

Peraturan Gubernur Jawa Tengah No 7 Tahun 2018 tentang Alokasi Dana Bagi Hasil Cukai Hasil Tembakau Bagian Pemerintah Provinsi Jawa Tengah dan Pemerintah Kabupaten/Kota di Jawa Tengah Tahun Anggaran 2018.

Peraturan Walikota Surakarta Nomor 27-C Tahun 2016 Tentang Kedudukan, Susunan Organisasi, Tugas, Fungsi dan Tata Kerja Perangkat Daerah Kota Surakarta

https://surakartakota.bps.go.id/Kota-Surakarta-Dalam-Angka/2018 diakses pada tanggal 11 Februari 2019 pukul 13.45 WIB 